\title{
The Representation of Women in
}

Publication: An Analysis of Political Communication and the International Journal of Press/Politics

Heather K. Evans, Sam Houston State University

Erik P. Bucy, Indiana University

ABSTRACT Scholarly publication in peer-reviewed journals is widely regarded as the road to scholarly success. However, in a diversity of fields such as sociology, economics, and political science, it has been shown that the rate of publication is much lower for women than for men. The question of whether a systematic relationship exists between gender and research methods has also frequently been debated. In this paper, we explore patterns of authorship and scholarship in two influential interdisciplinary journals, Political Communication and the International Journal of Press/Politics, over the last decade. A systematic content analysis was conducted to determine the gender ratio of authors, the methods and theories employed, and the ratio of quantitative to qualitative research studies. In addition, we tracked the use of primary or secondary data sources and the prevalence of research funding by gender. Overall, we find that while women are publishing less than men, their rate of publication is somewhat higher than their representation in the field.

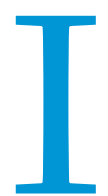

$\mathrm{n}$ the social sciences, as well as most academic disciplines, publication in scholarly journals is widely regarded as the path to success. Since the seventeenth century, journal publication has played an important role in post-secondary education (Zuckerman and Merton 1971). Journal publication is seen as a way to introduce new findings, theories, and arguments; legitimize and popularize one's work; and guide the discipline. Additionally, journal publication is widely viewed as an indicator of scholarly potential in the hiring and promotion of

Heather K. Evans is an assistant professor in the Department of Political Science at Sam Houston State University. Her research interests include political participation, elections and public opinion. She can be reached at hkeooz@shsu.edu.

Erik P. Bucy is an associate professor in the Department of Telecommunications and an adjunct associate professor in the Department of Political Science at Indiana University, Bloomington. His research interests include analysis of nonverbal communication in political news and normative theories of media and democracy. He is the author, with Maria Elizabeth Grabe, of Image Bite Politics: News and the Visual Framing of Elec-

tions, and the editor, with R. Lance Holbert, of the Sourcebook for Political Communication Research: Methods, Measures, and Analytical Techniques. He can be reached at ebucy@indiana.edu. faculty at colleges and universities. Irrespective of intellectual contribution, an individual faculty member's number of publications has been found to correlate highly with other forms of recognition and professional advancement (Guyer and Fidell 1973). For the general health of the discipline, therefore, it is important to periodically reflect on whether the publication playing field is level for everyone, and to assess the extent to which male and female scholars are publishing in recognized areas.

Research on publication trends and gender bias across the social sciences, including such fields as criminal justice, psychology, and political science (Clemente 1973; Eigenberg and Baro 1992; Guyer and Fidell 1973; Young 1995), consistently shows that male scholars publish much more frequently than female scholars. The publication rates of women deserve attention, because, as Bentley and Blackburn explain, "publications determine how reputations are earned, grants acquired, promotions awarded, [and] salaries ... allocated" (1992, 698). However, most studies of gender bias in publication are dated and only focus on a few key variables. The topic is worth our renewed attention, because it influences the distribution and visibility of research and the allocation of 
institutional rewards. Publication is the core of scholarly interchange. If publication processes have gender-related biases, then gender discrimination cannot be eliminated from scholarship without institutional changes.

This analysis contributes to the discussion of gender bias in the social sciences by examining the publication rate of male and female authors in two interdisciplinary journals: Political Communication and the International Journal of Press/Politics. In particular, we ask whether female authors differ from male authors in terms of sole- or multi-authorship, research support, areas of interest, and methodology. A systematic content analysis was conducted to determine the gender ratio of authors, the existence of funding sources, and the proportion of quantitative to qualitative research studies. In addition, we tracked the use of primary or secondary data sources, as well as the types of samples and methods employed. From a broader perspective, this article presents an opportunity for the field to assess scholarly inclinations and document research trends in political communication at a time of growing recognition of female scholars in political science (APSA Committee on the Status of Women 2001). The availability of accurate information about publication patterns should allow scholars to critically reflect on where the field has been-and where they would like for it to go.

\section{PUBLICATION RATES: AN INCOMPLETE STORY}

Using publication rates to address gender representation in any academic field tells an incomplete story. When looking specifically at publication rates, most studies have found that men publish more frequently than women (Blackburn and Holbert 1987; Kyvik 1990; Long 1990; Mathews and Andersen 2001). Male academics generally publish $40 \%$ to $50 \%$ more papers than do female scholars (Cole and Zuckerman 1984; Roland and FontanesiSeime 1996). Zuckerman states that "women publish fewer papers than men of the same ages, on average, 50-6o percent as many" (1991, 43). Men also receive substantially more citations to their work than do females (Cole and Singer 1991). These rates of publication and citation should not be surprising, because numerically, there are more men than women in the social sciences, as well as throughout the academy. Among individuals teaching political science in 2006, just $17 \%$ of full professors and $26 \%$ of professors overall were women (Sedowski and Brintnall 2007; see figure 1).

The issue of representation in the field differs from the issue of representation in publication, however. In publication, the proportion of female-authored articles is more important than the sheer number of articles. As Eigenberg and Baro point out in their analysis of women's participation in criminal justice journals, "the real issue is whether women participate in the publication process in proportion to their representation in the field" $(1992,294)$. Mathews and Andersen concur with this assertion in their examination of gender representation in political science book publishing: "What is at issue here is not female publishing productivity perse, but rather whether female political scientists are represented ... compared to their proportion in the discipline as a whole" $(2001,145)$.

Researchers across different fields have examined this issue and produced contradictory evidence. In psychology, some studies have found that women do publish in proportion to their representation in the field (e.g., White 1985), while other research has shown that women are underrepresented in their rate of publication (e.g., Kirk and Rosenblatt 1984). Gender representation

\section{Figure 1 \\ Percentage of Political Science Faculty by Rank and Sex, 20069}

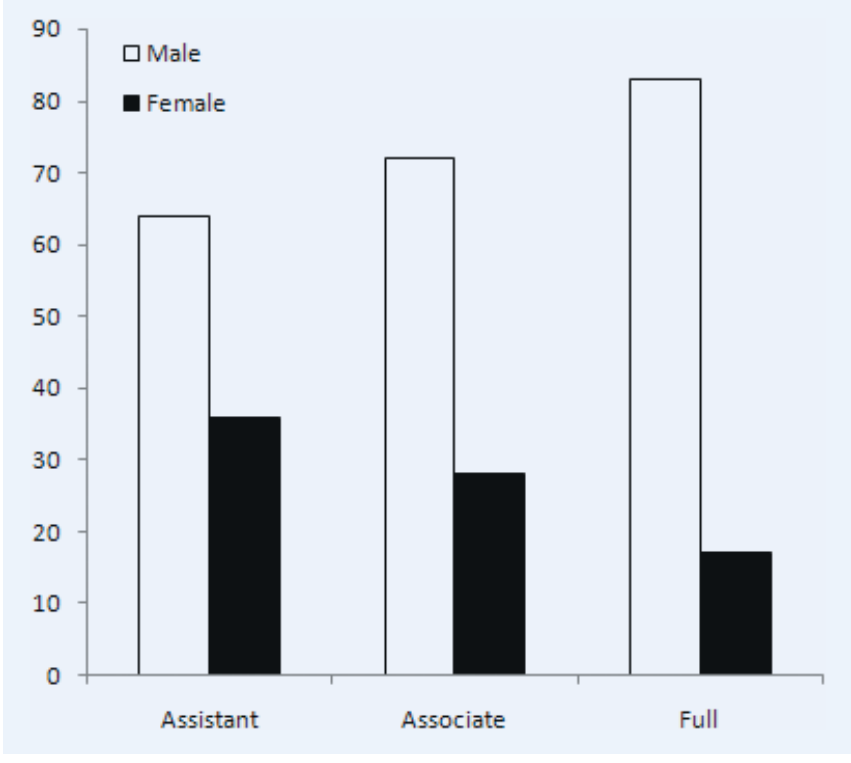

seems to vary by specific topics (Walker and Thompson 1984). A content analysis of educational psychology journals, for instance, found that women have become more involved in research publication over time (Robinson et al. 1998). Furthermore, in certain criminal justice journals, women are less likely to appear as lead authors, but are proportionately represented as co-authors (Moyer 1986).

In a study of gender representation in 15 political science journals over a 12-year period, Young (1995) found that single authorship among male scholars and same-sex ("males only") collaborations were among the most prominent trends in authorship. Female scholars have been successful in increasing their rate of publication, but Young's study did not address how publication rates compared to representation in the field overall. Because research on publication proceeds sporadically and is not consistently documented, there is no real consensus as to whether women are publishing at rates proportionate to their representation in the social sciences, including political science.

Our analysis addresses several questions about female publishing success. First, we determine the publication rates of female scholars in two interdisciplinary journals, Political Communication and Press/Politics, and specifically examine how often women appear as lead author. We then compare the ratio of male to female authors within the journals to two external sources: (1) the percentage of female authors cited in three major political communication review essays published in handbooks and annual reviews; and (2) the representation of women in the field, as evidenced by the memberships of the political communication divisions of both the American Political Science Association (APSA) and the International Communication Association (ICA). We also explore whether the publishing rates of women and men have been consistent across time in both journals and compare the research support awarded to female and male authors. Finally, the theories and methods used in articles with female authors are compared to those of male authors. 


\section{METHOD}

\section{Journal Selection}

Political Communication and Press/Politics were selected for analysis as model journals in political communication, a growing subfield in political science. ${ }^{1}$ Among the refereed journals in which political communication research is published, these two publications focus most exclusively on media and politics. Both journals are interdisciplinary in focus and have witnessed growing recognition and prestige with regard to other journals in both political science and mass communication. Their ranking represents the journals' general influence. Typically, the higher the ranking afforded to a journal, the greater the weight attached to the individual articles published within it. Both of these journals have a significant impact on the discipline, with high ratings in both mass communication and political science. According to ISI Journal Citation Reports (2005; Social Sciences Edition), Political Communication was ranked fourth by researchers in mass communication and ninth by researchers in political science in 2005 . Press/Politics, while not as strong as Political Communication, was ranked 16 th in mass communication and 19th in political science in $2005 .^{2}$

Because Political Communication and Press/Politics are read by and appeal to scholars in the fields of political science and communication (including journalism, mass communication, communication studies, and related areas), they ostensibly draw from a wider pool of researchers than do journals with a narrower focus. Both journals are open to different theoretical perspectives and methodological approaches and regularly publish articles by American and international scholars. Moreover, both journals were edited or co-edited by noted female scholars (Doris Graber and Pippa Norris) at different points in the analysis. Thus, we expected this diversity in focus, reach, and editorial guidance to be reflected by a corresponding diversity in authorship. Our assumption was that the journals' cross-disciplinary and international appeal would attract a greater range of authors than would be produced by a narrower area of expertise, resulting in higher publication rates for female authors, as compared to more traditional areas. On the other hand, if female scholars are not proportionately represented in these broad-gauge journals, then the field may indeed be facing even greater diversity pressures than is commonly realized.

\section{Sample and Coding Categories}

The sample for the study consisted of each issue of Political Communication from 1993 to 2006 and of Press/Politics from 1996 to 2006. Both journals are quarterlies. Only research articles that represented original analyses subjected to peer review were coded for analysis. Thus, we did not consider commentaries, review essays, position papers, interviews, or book reviews, which arguably play a lesser role in tenure and promotion cases at researchoriented universities. In all, 442 articles were analyzed, 257 from Political Communication and 185 from Press/Politics. The coding instrument consisted of numerous content categories related to gender and research focus, including lead author gender, the ratio of female to male authors for multiple-author articles, general research method (qualitative, quantitative, or a mixture of both), the data-gathering procedure (e.g., survey, experiment, focus group), theoretical framework, type of communication medium studied, and source of funding, if any. ${ }^{3}$
The gender of every author for each article was determined, and the lead author's gender was coded. Gender was primarily assessed by examining first names. For any author whose name was gender neutral (e.g., Lee, Leslie, Pat), or whose gender was initially unrecognizable-as might be the case with international scholars-an online search was conducted to determine the author's gender. If the article was written by more than one author, the article was coded for its gender ratio, using categories of all males, all females, more men than women, more women than men, and 50/50.

Articles were classified as quantitative if the method for gathering information on a target population was represented numerically. Quantitative research included mostly surveys, experiments, and content analyses. The article was coded as qualitative if the information gathered on the target population was not given a numeric value; these studies mostly used interviews, participant observations, discourse analyses, and focus groups. If more than one data-gathering procedure was used, the article was coded as using a mixture of both qualitative and quantitative methods.

Article coding also identified whether a theoretical framework guided the research in each study. First, we looked for any explicit mention of a theory within the article. When no theory was specifically mentioned, we examined whether any theory was strongly implied. When more than one theory was mentioned, we coded the dominant theory as primary and the other as secondary.

Acknowledgments and credit lines were examined to determine whether the research had been funded. Funding sources included intramural university or college awards, government funding, private foundation support, and other. If more than one organization provided funding, the category "multiple sources" was indicated.

To determine whether the publication of women within these two journals corresponded to their representation in the field, we compared the ratio of male to female authors to the percentage of female authors cited in three major political communication review essays (Swanson 2001, Graber 1993, and Graber 2002), as well as to the memberships of the political communication divisions of both APSA and ICA.

\section{FINDINGS}

To begin, we addressed the fundamental question of whether research by women in political communication is published at the same rate as research by men. As expected, we found that women publish less frequently than men, contributing to or authoring about $39 \%(n=172)$ of all articles analyzed, compared to $81.7 \%(n=361)$ for men. Next, we considered author placement, either trailing or lead. Consistent with other research, we assumed that being listed as a lead author "implies a greater contribution due to the increased responsibility as a principal investigator" (Robinson et al. 1998, 332). ${ }^{4}$ Only $25 \%(n=111)$ of research articles analyzed over our entire sampling period featured a female lead author. Although men appeared as the lead author in three out of four research articles, the percentage of studies with female lead authors still seems promising, given that an analysis of political science journals between 1983 and 1994 (a decade before our period of analysis) found that only $24 \%$ of the articles had even one female author (Young 1995).

When examining the journals separately, we found that women publish more as lead authors in Press/Politics than in Political Communication. This difference approaches significance, $\mathrm{chi}^{2}=5.68$, 
Figure 2

\section{Percentage of Female Lead Authors Over Time}

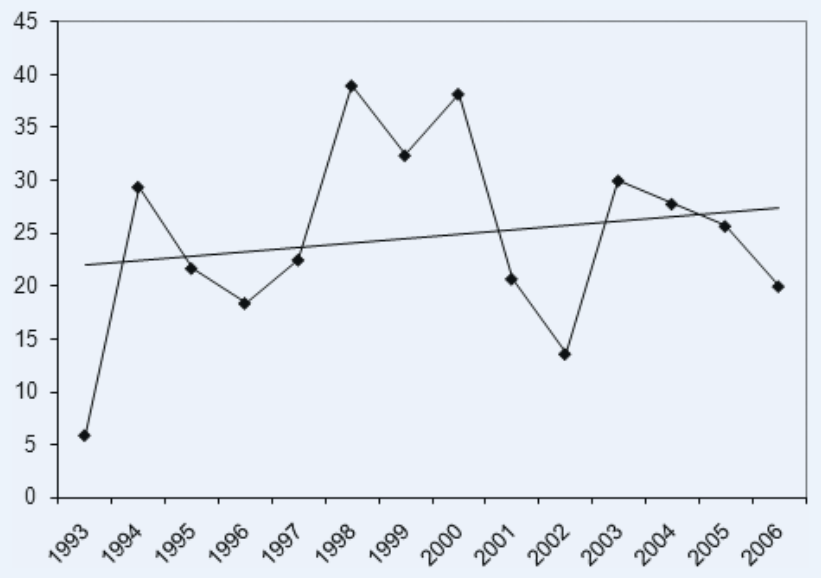

Figure 3

\section{Percentage of Female Lead Authors,} by Publication

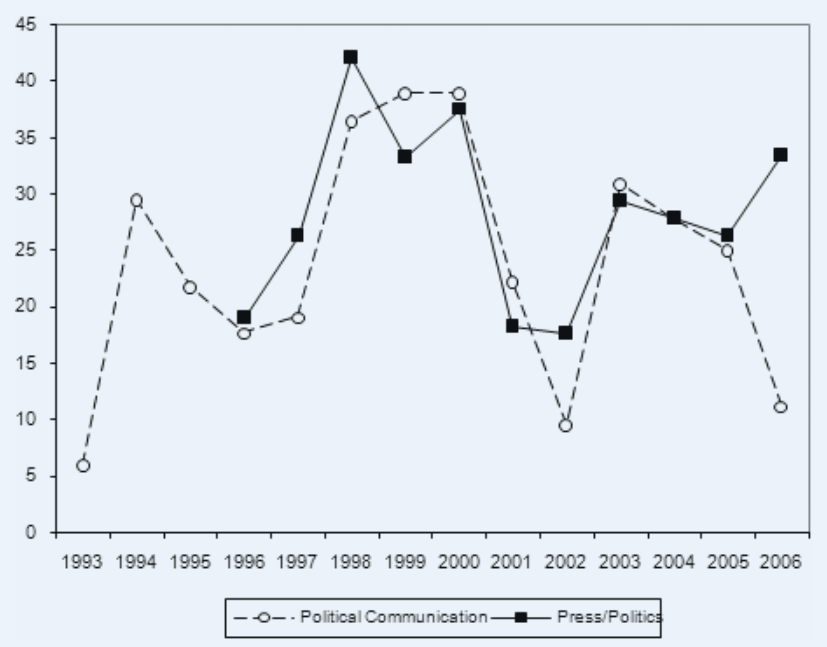

$2 d f, p<.10$. Over time, the percentage of female scholars publishing as lead authors increased, particularly from 1998 to 2001, when female lead authors published over $30 \%$ of the articles in the journals. Yet, lead authorship is variable. Despite gains, there has been a downward trend since 2001 in which the number of lead female authors has declined steadily (although it rebounded from 2003 to 2005). (See figure 2.)

Trends in lead authorship by female scholars were roughly equivalent across journals. The exception was 2006. If we were only examining average authorship rates, we could assume that the number of articles by female lead authors declined between 1998 and 2006 , from $39 \%$ to $20 \%$. As our data show, however, the publication rate of female lead authors rebounded from 2003 to 2005 and only declined thereafter in one journal, Political Communication (to 11.1\% in 2006). In Press/Politics, on the other hand, the female lead publication rate rose to over $33 \%$ in 2006. (See figure 3.)
Figure 4

\section{Gender Ratio of Multi-Author Papers}

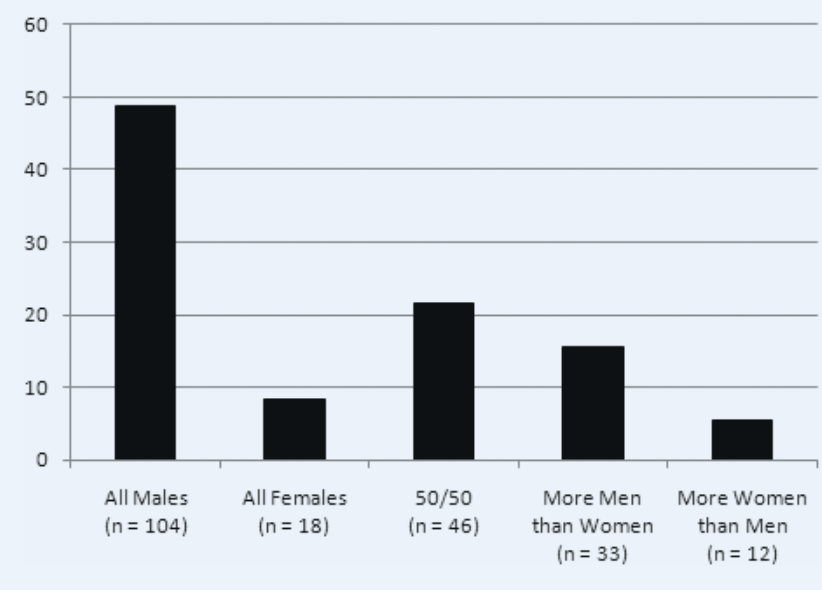

Multiple authorship rates were also examined to assess whether female scholars differed from male scholars with respect to their involvement in single-author articles, same-sex collaborations, and cross-sex collaborations. In our sample, $48 \%(n=213)$ of all articles were published by more than one author. To determine the proportion of male/female collaborations, each article's gender ratio (all females, all males, 50/50, more men than women, more women than men) was coded. As figure 4 shows, there were far more male-only than female-only collaborations. Only $4 \%$ of all research articles analyzed $(n=18)$ involved collaborations between women authors only. These studies were more likely to appear in Political Communication than Press/Politics. Whereas Political Communication featured 12 female-only collaborations (9.4\% of all multiple-author articles), Press/Politics featured just 6 femaleonly collaborations (7.1\% of all multiple-author articles).

Overall, $61.1 \%$ of the articles in both journals featured all-male authors; that is, six out of every 10 articles were written either by a male sole author or through a male-only collaboration. Female authors appeared in the other $38.9 \%$ of articles. Interestingly, women published more with members of the opposite sex $(55.2 \%$, $n=91)$ than as single authors $(33.9 \%, n=56)$ or in female-only collaborations $(10.9 \%, n=18)$.

Comparing these publication rates to the proportion of female scholars cited in three important political communication review essays, ${ }^{5}$ we found that women have higher publication rates within the journals we analyzed than were cited in the review essays. When examining only the journal citations within these works $(n=720)$, we found that women were cited as either lead or co-author in $27.2 \%(n=196)$ of all research articles. Of the authors who were cited and published after $1993(n=570), 29.3 \%$ were female $(n=$ 167). The rate of women's publication in Political Communication and Press/Politics (38.9\%) overall thus compares favorably.

Next, we examined whether women were represented in publication within these two journals proportionate to their presence in the field. To determine the proportion of female scholars in the field, we analyzed the membership lists of the political communication divisions of APSA and ICA (which together cosponsor the journal Political Communication). We found that women are actually better represented in both journals than they are proportionally represented as members within these two divisions. Some 
Table 1

\section{Theories by Lead Author Gender}

\begin{tabular}{lrlr} 
MEN & \% & \multicolumn{1}{c}{ WOMEN } & \% \\
\hline Democratic Theory & 12.1 & Framing & 19.8 \\
\hline Framing & 10.2 & Democratic Theory & 14.6 \\
\hline Media Influence on Politics & 9.2 & Feminism & 6.3 \\
\hline News Routines/Practices & 5.9 & Agenda Setting & 6.3 \\
\hline Media Bias & 3.7 & News Routines/Practices & 6.3 \\
\hline
\end{tabular}

27.6\% of the APSA political communication membership and $26.9 \%$ of the ICA political communication division are female, which means that women appear to be publishing in Political Communication and Press/Politics at a greater rate than their representation in the field. ${ }^{6}$

On the question of whether women and men have the same opportunities within the academy to pursue their research interests-namely, whether female scholars are receiving financial support at the same rate as male scholars-we find surprising results. Overall, only $21.5 \%$ of all the articles published in these two journals reported any funding, either through a grant or an award (24.9\% in Political Communication and $16.8 \%$ in Press/ Politics). Of those articles with funding, $28.4 \%$ were published by a female lead author. A higher percentage of female lead authors who were published in the journals received funding than male lead authors. Of those studies authored by a female lead, $24 \%$ received funding, compared to $20 \%$ of studies authored by a male lead author. For multi-author papers, $27.5 \%$ of research articles published with at least one female author received funding, compared to $28.8 \%$ of all-male collaborations.

Next, we asked whether the substantive area of research focus, study methods, or data sources differed by gender. Given that gender studies and related fields are typically dominated by female researchers (Tripp-Knowles 1995; Young 1995), we assumed that women would be more interested in gender-related and feminist research than men. The two journals were coded for whether articles specified a theory and, if so, which theories were used. By a small margin, articles with female leads (72.3\%) were more likely to specify a theory than articles with male lead authors (70.6\%), but the difference was not significant.

The primary theories used by male lead authors and female lead authors are listed in table 1 . Articles published by female leads were more likely to analyze media portrayals of the social, economic, and political inequality of women in society than articles published by male lead authors. Although women authors were more likely to publish studies related to women and gender than were men, women by no means exclusively focused on gender. Both democratic theory and framing were specified the most overall as primary theories. Next, we looked at who was most likely to specify a secondary theory. If a study did specify a secondary theory, for articles with male lead authors, the theory was typically media bias or framing (9.8\%); for articles with female lead authors, it was feminism (23\%). ${ }^{7}$

Women were also more likely than men to specify a method. All of the articles written by female lead authors specified a method, while not all of the articles written by a male lead author (91\%) specified a method. This difference was significant, chi $^{2}=$
Table 2

Methods by Lead Author Gender

\begin{tabular}{lrlr} 
MEN & \multicolumn{1}{c}{$\%$} & \multicolumn{1}{c}{ WOMEN } & \% \\
\hline Qualitative Content Analysis & 25.9 & Qualitative Content Analysis & 34.8 \\
\hline Quantitative Content Analysis & 13.9 & Case Study & 12.5 \\
\hline Survey (One-Shot/Secondary) & 9.5 & Quantitative Content Analysis & 10.7 \\
\hline Survey (Panel/Secondary) & 8.5 & Survey (One-Shot/Original) & 8.9 \\
\hline Survey (One-Shot/Original) & 8.2 & Experiment (Lab) & 8.0 \\
\hline
\end{tabular}

Table 3

General Research Approach by Lead Author Gender

\begin{tabular}{lcc} 
& MEN & WOMEN \\
\hline Qualitative & $30 \%$ & $50 \%$ \\
& $(n=97)$ & $(n=56)$ \\
\hline Quantitative & $35.6 \%$ & $16.1 \%$ \\
& $(n=115)$ & $(n=18)$ \\
\hline Mixed Method & $14.6 \%$ & $16.1 \%$ \\
& $(n=47)$ & $(n=18)$ \\
\hline Descriptive & $19.8 \%$ & $17.8 \%$ \\
& $(n=64)$ & $(n=20)$ \\
\hline
\end{tabular}

$11.4,2 d f, p<.01$. The types of methods employed also differed by the gender of the lead author. Both female and male lead authors used qualitative content analyses most often. Secondary one-shot surveys and panel surveys were among the top five specified methods for male lead authors, while case studies and experiments were among the top five for female lead authors (see table 2).

One might assume, therefore, that both women and men publish qualitative research more often than quantitative research. Looking at whether each study was qualitative, quantitative, a mixture of both, or descriptive, we found that articles written by female lead authors were primarily qualitative. About two-thirds (66.1\%) of the articles published by a female lead were qualitative or mixed methods, while less than half (44.6\%) of the studies published by a male lead author were qualitative or mixed methods. Male scholars were significantly more likely to publish quantitative studies than female scholars, $\mathrm{chi}^{2}=27.87,6 d f, p<.01$. For male authors, $35.6 \%$ of their articles were strictly quantitative. Only $16.1 \%$ of the articles published by female lead authors used quantitative methods only (see table 3 ).

\section{DISCUSSION}

This examination of the publication rates of male and female scholars in a dynamic interdisciplinary subfield uncovers some interesting patterns and revealing results. While male-only work remains the most frequently occurring authorship trend, 39\% of all research articles analyzed were written by at least one female author, which is substantially higher than both the citation rate presented in the three review essays with which we compared the journals and the rate at which women are represented in the political communication divisions of APSA and ICA. Because publication is key to advancing one's academic career, these results are 
promising. Indeed, the percentage of articles published by female lead authors has risen over time. To build a reputation, an individual faculty member typically must have a successful record of publication. Our research shows that women, when they do appear in print in the two leading political communication journals, are publishing more frequently as lead authors than they did in the past.

Among the female-authored work within these two journals, the dominant pattern of authorship is cross-sex collaborations. Over half of the articles published by women (55.2\%) resulted from cross-sex collaborations. In contrast, male scholars were more likely to publish as sole authors (46.4\%) or with other male researchers (29.3\%) than to publish with women $(24.3 \%)$. Female scholars were more likely to publish alone $(33.9 \%)$ than with other women (10.9\%). Multiple-author, female-only articles represented a very small percentage of the articles published in the two journals (4\%).

These data show that when women publish, they are more likely to publish with men than alone or with other women. Are female scholars in political communication therefore less independent than male scholars? Although the immediate temptation might be to answer in the affirmative, some have argued that collaboration could just as easily indicate women's fuller integration into the discipline (see Mackie 1985). This content analysis cannot definitively answer this question. Nevertheless, if co-authored work is positively evaluated within the field, then ically rigorous research because of their minority status in many social scientific journals, perhaps reasoning that they must clear a higher bar to achieve acceptance. Alternatively, journal editors may be more demanding of female authors. In either case, by explicitly detailing a theory and method in their research papers, female scholars maximize their chances for success. ${ }^{8}$

Women and men also specialize in different areas of research. Women are more likely to publish research using feminist theory, but they do not focus exclusively on this area. Framing and democratic theory are the most popular theories in both female and male lead-author work. Methodologically, both male and female authors use content analysis most often in their research. Overall, women are significantly more likely to publish qualitative work, while men tend to publish more quantitative work. Half of the studies published by female lead authors were qualitative in nature.

When examining the proportion of research published by women in these two journals compared to their presence in notable review essays and divisional memberships in professional associations, we found that women published at a rate greater than their representation in the field. Overall, $38.9 \%$ of the articles published in Political Communication and Press/Politics featured at least one female author, while only $27 \%$ of APSA and ICA political communication division members are female. It seems, therefore, that women are not underrepresented in the interdisciplinary field of political communication research.

\section{Women lead authors were significantly more likely to specify a theory and a methodology in their research. Does this suggest that women are more careful researchers than men, or at least more careful to document the details of their conceptual approach and research design? Women may feel pressured to submit more methodologically rigorous research because of their minority status in many social scientific journals, perhaps reasoning that they must clear a higher bar to achieve acceptance.}

collaborations of any sort should be viewed as a positive sign for women's representation in political communication.

A potential obstacle to female research collaborations is that women scholars in specialized areas or subfields may have difficulty locating other women with similar research interests. In many departments, only one female faculty member may be interested in political communication. Perhaps as more women are hired into both political science and communication departments, there will be an increase in female collaboration.

In terms of research support, women and men appear to receive research funding at a similar rate. Although only $21.5 \%$ of all research articles analyzed reported any type of financial support, a slightly higher percentage of studies with female lead authors received funding than did those with male lead authors, although this difference was not statistically significant. This lack of difference is noteworthy.

The type of research published and the way it was reported by male and female authors differed in interesting ways. Women lead authors were significantly more likely to specify a theory and a methodology in their research. Does this suggest that women are more careful researchers than men, or at least more careful to document the details of their conceptual approach and research design? Women may feel pressured to submit more methodolog-
Are the publications by female lead authors dominated by a few key authors? If this is the case, then the encouraging results about representation in the field may need to be reevaluated. According to our results, 95 female researchers were listed as a lead author in these two journals. Only 14 of these authors were listed as a lead author more than once during the years under study, and none had more than three lead-author publications. Our results are a positive sign for gender representation in publication.

Although this study examining publication rates in two influential interdisciplinary journals provides some important insights, work remains. A larger sample that includes more journals might yield different results. To truly examine the wider representation of women in publication, it is necessary to carefully assess what the productivity rates of female scholars should be within peerreviewed journals. Should representation be measured by the percentage of women in the field, the percentage of papers presented at conferences, or some other yardstick? Such questions await further analyses and debate.

\section{NOTES}

The authors would like to thank Colleen McClain for her generous and able research assistance. An earlier version of this paper was presented at the 2008 annual meeting of the Midwest Political Science Association, Chicago, IL. 
1. As a subfield, political communication is formally recognized by the main professional associations in both political science (e.g., APSA, MPSA) and communication (e.g., ICA, National Communication Association [NCA]) Indeed, the journal Political Communication is cosponsored by the political communication divisions of APSA and ICA. Graber, a former editor of Political Communication, has described this cross-disciplinary area as "an extremely important subfield of political science" $(1993,305)$ that has made "rapid strides in a brief period of time" (306). As a sign of its growing stature, political communication was included as a recognized subfield in the reference volume Political Science: State of the Discipline II (Finifter 1993), published by APSA.

2. 93 journals were included in the political science ranking and 45 in the mass communication ranking.

3. Ten percent of the articles were double-coded independently by a second trained coder to ensure intercoder reliability. The analysis reflected an acceptable level of agreement between the primary author and the second trained coder.

4. We grant that in some research communities and working groups, authorship order is alphabetical. Given our experiences within the communication and political science disciplines, in which second-author publications may count less toward tenure and promotion, we assume that lead author status generally denotes greater contribution.

5. The three references used for this comparison were Swanson (2001), Graber (1993), and Graber (2002). All authors listed in these references are included in the comparison $(N=1,765)$. Overall, $22.8 \%$ of all listed authors were female; $19.8 \%$ were book authors, $13.6 \%$ were book editors, $22.2 \%$ were authors of chapters in edited volumes, and $\mathbf{2 7 . 2} \%$ were authors of research articles.

6. For the APSA political communication division $(N=489)$, the number of female members was 135 . For the ICA political communication division $(N=$ 770 ), the number of female members was 207. We would like to thank Richard Davis of Brigham Young University and Deandra Harris of ICA for this information.

7. Out of the 64 articles that specified a secondary theory, 51 were published by a male lead author and 13 were published by a female lead.

8. A survey of women in the political communication field is needed to explore the reasons for these differences.

9. Data are from APSA's database of all political science faculty (see http:// www.apsanet.org).

\section{REFERE N C ES}

APSA Committee on the Status of Women. 2001. "The Status of Women in Political Science: Female Participation in the Professoriate and the Study of Women and Politics in the Discipline." PS: Political Science and Politics 34: 319-26.

Bentley, Richard J., and Robert Blackburn. 1992. "Two Decades of Gains for Female Faculty?" Teachers College Record 93 (4): 697-709.

Blackburn, Robert, and Betty Holbert. 1987. "The Careers of Women in Academia." In The Trapped Woman, ed. J. Figuerira-McDonough and R. Sarri, 296317. Beverly Hills, CA: Sage.

Clemente, Frank. 1973. "Early Career Determinants of Research Productivity." American Journal of Sociology 79: 409-19.

Cole, S., and B. Singer. 1991. "A Theory of Limited Differences." In The Outer Circle: Women in the Scientific Community, ed. H. Zuckerman, J Cole, and J. T. Bruer, 27-56. New York: Norton.

Cole, Jonathan, and Harriet Zuckerman. 1984. "The Productivity Puzzle: Persistence and Change in Patterns of Publication of Men and Women Scientists." In Advances in Motivation and Achievement, Vol. 2, ed. P. Maehr and M. W. Steinkamp, 217-58. Greenwich, CT: JAI Press.

Eigenberg, Helen, and Agnes Baro. 1992. "Women and the Publication Process: A Content Analysis of Criminal Justice Journals." Journal of Criminal Education 3 (2): 293-314
Finifter, Ada W., ed. 1993. Political Science: State of the Discipline II. Washington, DC: American Political Science Association.

Graber, Doris A. 1993. "Political Communication: Scope, Promise, Progress." In Political Science: State of the Discipline II, ed. Ada W. Finifter, 305-32. Washington, DC: American Political Science Association.

. 2002. Mass Media and American Politics. 6th ed. Washington DC: Congressional Quarterly.

Gudykunst, William B., ed. 2001. Communication Yearbook 24. Newbury Park, CA: Sage.

Guyer, Larue, and Linda Fidell. 1973. "Publications of Men and Women Psychologists.” American Psychologist 57 (1): 154-6o.

ISI Journal Citation Reports Social Sciences Edition. 2005. Thomson Reuters.

Kirk, Stuart, and Aaron Rosenblatt. 1984. "The Contribution of Women Faculty to Social Work Journals." Social Work 29 (1): 67-69.

Kyvik, Svein. 1990. "Motherhood and Scientific Productivity." Social Studies of Science 20: 149-6o.

Long, J. Scott. 1990. “The Origins of Sex Differences in Science.” Social Forces 68 (4): $1297-1315$.

Mackie, Marlene. 1985. "Female Sociologists' Productivity, Collegial Relations, and Research Style Examined Through Research Publications." Sociology and Social Research 69: 189-209.

Mathews, A. Lanethea, and Kristi Andersen. 2001. "A Gender Gap in Publishing? Women's Representation in Edited Political Science Books." PS: Political Science and Politics 34 (1): 143-47.

Moyer, Imogene. 1986. "Gatekeepers for Academic Criminology: An Exploratory Study of the Status of Women." Paper presented at the Twelfth International Conference on Improving University Teaching, Heidelberg, Germany, July $15-18$.

Robinson, Daniel H., Dakin W. McKay, Andrew D. Katayama, and Ai-Chun Fan 1998. "Are Women Underrepresented as Authors and Editors of Educational Psychology Journals?” Contemporary Educational Psychology 23: 331-43

Roland, Catherine Buffalino, and Margaret Fontanesi-Seime. 1996. "Women Counselor Educators: A Survey of Publication Activity." Journal of Counseling and Development 74: 490-95.

Sedowski, Leanne, and Michael Brintnall. 2007. "Data Snapshot: The Proportion of Women in the Political Science Profession." American Political Science Association: http://www.apsanet.org/imgtest/Website\%2obrief\%20on\%20 women\%2oin \%20PS\%20v2\%201\%202007.pdf.

Swanson, David L. 2001. "Political Communication Research and the Mutations of Democracy.” In Communication Yearbook 24, ed. William B. Gudykunst, 189205. Thousand Oaks, CA: Sage.

Tripp-Knowles, Peggy. 1995. "A Review of the Literature on Barriers Encountered by Women in Science Academia." Resources in Feminist Research 24: 28-34.

Walker, Alexis, and Linda Thompson. 1984. "Feminism and Family Studies." Journal of Family Issues 5 (4): 545-70.

White, Arden. 1985. "Women as Authors and Editors of Psychology Journals: A Ten Year Perspective." American Psychologist 40: 527-61.

Young, Cheryl D. 1995. "An Assessment of Articles Published by Women in 15 Top Political Science Journals." PS: Political Science and Politics. 28 (3): 525-33.

Zuckerman, Harriet. 1991. "The Careers of Men and Women Scientists: A Review of Current Research." In The Outer Circle: Women in the Scientific Community, ed. H. Zuckerman, J. R. Cole, and J. T. Bruer, 277-310. New York: W.W. Norton.

Zuckerman, Harriet, and Robert K. Merton. 1971. "Patterns of Evaluation in Science: Institutionalisation, Structure, and Functions of the Referee System." Minerva 9: 66-100. 


\section{Canadian Journal of Political Science}

\author{
English Editor \\ Csaba Nikolenyi \\ Concordia University, Canada
}

French Editor

Nicole F. Bernier

Université de Montréal, Canada

Published for the

Canadian Political Science Association/

Association canadienne de science politique (CPSA/Acsp) and the

Société québécoise de science politique (Sqsp)

This peer-reviewed journal provides original research articles, notes, commentaries, review articles, and book reviews in all areas of political science, including but not limited to: the history of political thought; contemporary political theory; international relations and foreign policy; governmental institutions and processes; political behavior; public administration and public policy; and women and politics.

In addition, the Canadian Journal of Political Science/ Revue canadienne de science politique is the primary forum for innovative research on all facets of Canadian politics and governmentas well as the principal outlet for Canadian political science scholarship.

Submissions are accepted in English and in French.

\section{Revue canadienne de science politique}

Directeur anglophone Csaba Nikolenyi

Concordia University, Canada

Directrice francophone Nicole F. Bernier

Université de Montréal, Canada

Revue publiée pour l'Association canadienne de science politique/ Canadian Political Science Association (Acsp/CPSA) et la Société québécoise de science politique (Sqsp)

Cette revue soumise à l'évaluation des pairs offre des articles de recherche originaux, des notes, des commentaires, des exposés de synthèse et des recensions dans tous les domaines de la science politique, notamment: l'histoire de la pensée politique,

la théorie politique contemporaine,

les relations internationales et la politique étrangère, les institutions publiques et les processus gouvernementaux,

les comportements politiques, l'administration et les politiques publiques, et les femmes et la politique. En outre,

la Canadian Journal of Political Science/

Revue canadienne de science politique est le forum dechoix des spécialistes de tous les aspects de la vie politique et du gouvernement au Canada, ainsi que la principale tribune des chercheurs canadiens en science politique.

Les articles peuvent être rédigésen anglais ou en français.
Quarterly, Volume 43, 2010

Institutions print and online: \$127 / £79

Print ISSN 0008-4239

Online ISSN 1744-9324

Cambridge University Press

32 Avenue of the Americas

New York, NY 10013-2473 USA

Tel: 800-872-7423 • Fax: 845-353-4141

Email: journals_subscriptions@cambridge.org

Web: http://journals.cambridge.org
Revue trimestrielle, Volume 43, 2010 Institutions - version imprimée et en ligne: \$127 / £79

Version imprimée ISSN 0008-4239

Version en ligne ISSN 1744-9324

Cambridge University Press 32 Avenue of the Americas New York, NY 10013-2473 USA Tél.: 800-872-7423 • Téléc.: 845-353-4141 Courriel: journals_subscriptions@cambridge.org Web: http://journals.cambridge.org 